\title{
XLIX.-Contributions to our Knowledge of the Aconite Alkaloids. Part XI. The Constitution of Aconitine. Acetyl Derivatives of Benzaconine and Aconitine.
}

By Wrndham R. Dunstan, M.A., F.R.S., and Francts H. Carr, Salters Company's Research Fellow in the Research Laboratory of the Pharmaceutical Society.

Is previous communications (Parts $I X$ and $X$, Trans., 1894, 65, 176 and 290), the authors showed that when aconitine is heated at its melting point forming pyraconitine, or when partially hydrolysed forming benzaconine, or when it is completely hydrolysed forming aconine, a molecular proportion of acetic acid is separated; from this it follows that aconitine must be regarded as a monacetyl derivative, namely, acetylbenzoylaconine $\left(\mathrm{C}_{33} \mathrm{H}_{45} \mathrm{NO}_{12}\right)$.

During the past year, experiments have been made with the view of re-forming aconitine from benzaconine by introducing an acetyl group into it, and thus confirming the correctness of the constitution deduced from analytical evidence. Althongh the acetylation of benzaconine has been carried out under various conditions, it has not, so far, been possible to prepare aconitine; diacetyl, triacetyl, and tetracetyl derivatives being formed, which are non-poisonous. Up to the present, no monacetyl derivative of benzaconine isomeric with aconitine has been obtained.

Diacetylbenzaconine, $\mathrm{C}_{31} \mathrm{H}_{41}\left(\mathrm{CH}_{3} \mathrm{CO}\right)_{2} \mathrm{NO}_{11}$. This compound is prepared by acting on benzaconine dissolved in chloroform with a small excess of acetic anhydride at the ordinary temperature. It is an amorphous base insoluble in water, but easily soluble in ether or chloroform. The hydrobromide crystallises readily from alcohol on adding ether to the solution. It is found that when rapid crystallisation is caused by the copious addition of ether, the substance melts at $214^{\circ}$, but when crystallised slowly it melts at $265^{\circ}$. We have had occasion to draw attention to a similar behaviour of the salts of other alkaloïds of this group.

This derivative, apparently, is not toxic, and could not be made to 
yield a toxic alkaloïd by slow hydrolysis either with alkali or water the product first formed in the former case being aconine, and in the latter benzaconine. The amount of acetic acid eliminated on hydrolysis was estimated, and found to be 16.2 per cent.; the quantity required by diacetylbenzaconine hydrobromide is 15.6 per cent. The method of hydrolysis employed in this case, as in all of those to be described, consists in dissolving a weighed amount of the substance in pure alcohol, adding pure sodium hydroxide solution, and then heating to $70^{\circ}$. An hour is sufficient to complete the action. The solution, after being nearly neutralised with dilute sulphuric acid, is evaporated (and in this particular case the haloid acid was removed by precipitation with silver sulphate). It is next repeatedly distilled with dilute sulphuric acid until no more volatile acid is obtained; the distillate is then shaken with benzene to remove benzoic acid, and titrated with $\mathrm{N} / 20$ soda solution.

Triacetylbenzaconine, $\mathrm{C}_{31} \mathrm{H}_{40}\left(\mathrm{CH}_{3} \cdot \mathrm{CO}\right)_{3} \mathrm{NO}_{11}$.-This derivative is obtained by acting on a chloroform solution of benzaconine with acetic anhydride at $100^{\circ}$, or at the ordinary temperature in the presence of sodium acetate. It is crystalline, melts at $255-256^{\circ}$, and dissolves in alcohol and in ether, but not in water. Neither the base nor its salts produce any tingling when applied to the tongue, and, apparently, are not poisonous in small doses.

When completely hydrolysed with alkali, this substance furnishes aconine, benzoic acid, and acetic acid. The amount of acetic acid produced is 24.4 per cent., which agrees with the quantity required for a triacetyl derivative, namely, $24: 6$ per cent.; a diacetyl derivative requires $17 \cdot 4$ per cent. and a monacetyl derivative $9 \cdot 27$ per cent. Experiments were made on the partial hydrolysis of this base in the hope of obtaining a monacetyl derivative, but they were unsuccessful.

This triacetyl derivative appears to be the same as that described by Messrs. Freund and Beck (Ber., 1894, 27, 7321) as a monacetyl derivative. These observers, howerer, relied entirely on the results of combustions in determining the composition, and, as is well known, this is fallacious in cases like the present one, where the addition or removal of an acetyl group makes but little difference in the percentage composition. From the calculated percentages of carbon and hydrogen for monacetyl, diacetyl, and triacetyl derivatives tabulated below, it will be seen that even between the mono- and tri-substitution derivatives the percentage differences are small, whilst, on the other hand, the large differences in the percentages of acetic acid furnished by the hydrolysis of these substances affords a safe criterion of the number of acetyl groups which have been introduced. 
$\mathrm{C}_{31} \mathrm{H}_{42}\left(\mathrm{CH}_{3} \cdot \mathrm{CO}\right) \mathrm{NO}_{11} . \mathrm{C}=61 \cdot 20 ; \mathrm{H}=6.95 ;$ acetic acid $=9 \cdot 27$ per cent.

$\mathrm{C}_{31} \mathrm{H}_{41}\left(\mathrm{CH}_{3} \cdot \mathrm{CO}\right)_{2} \mathrm{NO}_{11} . \quad \mathrm{C}=60 \cdot 96 ; \mathrm{H}=6 \cdot 82 ;$ acetic acid $=17 \cdot 41$ per cent.

$\mathrm{C}_{31} \mathrm{H}_{40}\left(\mathrm{CH}_{3} \cdot \mathrm{CO}\right)_{3} \mathrm{NO}_{11} . \quad \mathrm{C}=60 \cdot 74 ; \mathrm{H}=6 \cdot 70 ;$ acetic acid $=24 \cdot 62$ per cent.

When acetyl chloride is used as the acetylating agent in place of acetic anhydride, a different product is obtained. By allowing the chloride to stand for some hours with benzaconine, or one of its salts. dissolved in chloroform, and then regenerating the base from the saline residue by means of dilute ammonia and extracting with ether, a crystalline base was obtained which melted at $162^{\circ}$. This is insoluble in water, and does not dissolve readily in dilute acids. The hydrobromide is crystalline, and melts at $231^{\circ}$ after re-crystallisation from a mixture of alcohol and ether. The aurichloride, which is amorphous, contains $16 \cdot 6$ per cent. of gold.

Great difficulty was experienced in deciding as to the composition of this substance. It is not easy to dry it completely in a desiccator, and on prolonged heating at $100^{\circ}$ it suffers some decomposition; concordant results, therefore, were not obtained on combustion. When dried for three hours, it lost about 4 per cent. of water, and on complete hydrolysis with alkali it furnished $25.8 \mathrm{per}$ cent. of acetic acid, in addition to benzoic acid and aconine. The substance would seem, therefore, to be a tri-hydrate of triacetylbenzaconine, but this constitution cannot be regarded as established. It is not toxic in small doses, and no monacetyl-derivative could be obtained from it by partial hydrolysis.

Tetracetylbenzaconine, $\mathrm{C}_{31} \mathrm{H}_{39}\left(\mathrm{CH}_{3} \mathrm{CO}\right)_{4} \mathrm{NO}_{11}$. -We have previously pointed out that aconitine forms an aurichloride of the usual type. Benzaconine, however, which is formed from aconitine by the hydrolytic separation of its acetyl group, furnishes a remarkable colourless a urichlor-derivative, $\mathrm{C}_{31} \mathrm{H}_{12}\left(\mathrm{AuCl}_{2}\right) \mathrm{NO}_{11}$, and from this it would appear that the atom of hydrogen in benzaconine which is replaced by the residue $\mathrm{AnCl}_{2}$ is the same as that which is replaced by an acetyl group in aconitine. It seemed probable, therefore, that if the group $\mathrm{AuCl}_{2}$ in this compound were replaced by acetyl, aconitine would be formed. It was found, however, that reaction hetween the gold salt and acetyl chloride does not readily take place; at $100^{\circ}$ in a closed tube, on the other hand, the aurichlor-derivative is decomposed, and from the residue a crystalline base is obtained melting at $211^{\circ}$. It is insoluble in water, but dissolves in alcohol and in ether; dilute acids dissolve it with great difficulty. The same substance may be obtained by heating benzaconine with acetyl chloride, in a closed tube at $100^{\circ}$. It is not poisonons, and is remarkable in forming 
a colourless aurichlor-derivative (m. p. 225 ) containing 18.2 per cent. of gold. As, on hydrolysis, this base furnishes 33.8 per cent. of acetic acid, besides benzoic acid and aconine, it appears to be a tetracetylbenzaconine, the aurichlor-derivative of which would contain 18.8 per cent. of gold, and would furnish $3 \mathrm{l} \cdot 16$ per cent. of acetic acid on hydrolysis.

It will be seen from these results that it has not been possible to prepare a monacetylbenzaconine corresponding with aconitine, whilst the higher acetyl derivatives which have been prepared differ from aconitine in not being highly poisonous. The exact physiological action of these derivatives is being investigated by Professor Cash, F.R.S., of Aberdeen.

We proceeded, in the next place, to determine whether we could prepare triacetylbenzaconine and tetracetylbenzaconine, taking aconitine as a starting point instead of benzaconine. Aconitine being acetylbenzaconine, its diacetyl-derivative should correspond with triacetylbenzaconine and its triacetyl-derivative with tetracetylbenzaconine.

Acetic anhydride does not react with aconitine, even after prolonged standing or heating at $100^{\circ}$.

Triacetylaconitine.-When acetyl chloride in large excess is allowed to act on aconitine at the ordinary temperature during a day, in the absence of a solvent, a crystalline base may be extracted with ether in the usual manner. It melts at $207^{\circ}$, and crystallises in fine needles from its alcobolic solution, especially after the addition of ether, in which it is sparingly soluble. It dissolves with difficulty in dilnte acids. and its salts are unstable. On combustion this substance furnished the following data.

$0 \cdot 2068$ gave $0.4572 \mathrm{CO}_{2}$ and $0 \cdot 1314 \mathrm{H}_{2} \mathrm{O} . \mathrm{C}=60 \cdot 30 ; \mathrm{H}=7 \cdot 06$ per cent. $\mathrm{C}_{33} \mathrm{H}_{42}\left(\mathrm{CH}_{3} \cdot \mathrm{CO}\right)_{3} \mathrm{NO}_{12}$ requires $\mathrm{C}=60 \cdot 54 ; \mathrm{H}=6.59$ per cent.

On hydrolysis, this base furnished aconine, benzoic acid, and 31 per cent. of acetic acid; an amount which corresponds with the calculated quantity for triacetylaconitine ( $31 \cdot 16$ per cent.).

In addition to this substance, a small quantity of another, and apparently non-basic, compound is formed by the action of acetyl chloride on aconitine, but this was not further examined.

This triacetylaconitine is isomeric, and not identical with the tetracetylbenzaconine described above. Not only do these two substances differ in physical properties, but the former compound has the characteristic physiological action of aconitine, whilst the derivative prepared from benzaconine has not.

Diacetylaconitine.-This compound was prepared by acting with acetyl chloride on aconitine, or on one of its salts, either in the dry 
state or dissolved in chloroform for several hours at the ordinary temperature. It is a crystalline base melting at $158^{\circ}$, only slightly soluble in water, but readily in alcohol or chloroform, less so in ether. The combustion of the base furnished the following data.

$$
\begin{aligned}
& 0.1775 \text { gave } 0.3974 \mathrm{CO}_{2} \text { and } 0.1126 \mathrm{H}_{2} \mathrm{O} . \quad \mathrm{C}=61.06 ; \mathrm{H}=7.05 \text {. } \\
& 0.1607,0.3607 \mathrm{CO}_{2}, 0 \cdot 1607 \mathrm{H}_{2} \mathrm{O} . \quad \mathrm{C}=61 \cdot 21 ; \mathrm{H}=7 \cdot 01 \text {. } \\
& 0.1884, \quad 0.4191 \mathrm{CO}_{2}, 0.1208 \mathrm{H}_{2} \mathrm{O} . \quad \mathrm{C}=60.67 \text {; H }=7 \cdot 11 \text {. } \\
& \mathrm{C}_{33} \mathrm{H}_{43}\left(\mathrm{CH}_{3} \cdot \mathrm{CO}\right)_{2} \mathrm{NO}_{12} \text { requires } \mathrm{C}=60 \cdot 74 ; \mathrm{H}=6.7 \text { per cent. }
\end{aligned}
$$

If auric chloride is added to a solution of the hydrochloride of this base, a yellow, amorphous precipitate is thrown down, and when this is dissolved in alcohol and crystallised by adding a mixture of ether and light petroleum, fine, white needles (m. p. $164^{\circ}$ ) of an aurichloroderivative are obtained. The following are the results of an analysis of this compound.

0.1683 gave $0.0318 \mathrm{Au}$ and $0.0434 \mathrm{AgCl} . \quad \mathrm{Au}=18.89 ; \mathrm{Cl}=6.29$. $\mathrm{C}_{33} \mathrm{H}_{42}\left(\mathrm{CH}_{3} \cdot \mathrm{CO}\right)_{2} \mathrm{AuCl}_{2} \mathrm{NO}_{12}$ requires $\mathrm{Au}=19 \cdot 65 ; \mathrm{Cl}=7.08$ per cent.

On alkaline hydrolysis, the base yielded aconine, benzoic acid, and 25.58 per cent. of acetic acid; the calculated quantity for diacetylaconitine is 24.62 per cent.

The physiological action of diacetylaconitine probably resembles that of aconitine, since it produces the characteristic tingling sensation. In this respect, as well as in physical and chemical properties, it differs from its isomeride triacetylbenzaconine.

Triacetylpyraconitine. - When pyraconitine hydrochloride, dissolved in chloroform, is acted on in the cold with acetyl chloride, a crystalline base melting at $204^{\circ}$ is produced; it is insoluble in water, but dissolves in ether and in alcohol. This substance does not appear to. be toxic. On combustion it furnished the following data.

0.1863 gave $0.4394 \mathrm{CO}_{2}$ and $0.1318 \mathrm{H}_{2} \mathrm{O} . \quad \mathrm{C}=64.32 ; \mathrm{H}=7.8$.

$0.1807,0.4214 \mathrm{CO}_{2}, 0.1288 \mathrm{H}_{2} \mathrm{O} . \quad \mathrm{C}=63.60 ; \mathrm{H}=7.91$.

The mean percentages are $\mathrm{C}=63.92, \mathrm{H}=7 \cdot 85$, which are in fair agreement with those calculated from the formula

$$
\mathrm{C}_{31} \mathrm{H}_{40}\left(\mathrm{CH}_{3} \cdot \mathrm{CO}\right)_{3} \mathrm{NO}_{10},
$$

which requires $\mathrm{C}=63.8 ; \mathrm{H}=6.47$ per cent. On hydrolysis, it afforded 22.6 per cent. of acetic acid, whilst the percentage calculated for the above formula is 88.02 per cent.

This derivative corresponds more closely with those of benzaconine than with those of aconitine, especially in not possessing the characteristic physiological action of the derivatives of the latter alkaloïd.

So far, then, all attempts to convert benzaconine into aconitine 
have failed, the other methods of acetylation which were employed having given negative results. The distinct characters, especially the different physiological action of the two sets of corresponding derivatives from benzaconine and aconitine, are somewhat difficult to understand, and the exact constitution of aconitine and its relation to benzaconine is a problem which still requires further elacidation.

We are unwilling to enter again into a discussion of priority with Messrs. Freund and Beck as to the establishment of the new view of the constitntion of aconitine, but the fresh reply to our claim which Herr Freund (Ber., 1895, 28, 192), after the lapse of a year, has been led to make, renders it necessary for us to call attention to the facts of the case.

In the Proceedings of this Society recording the meeting of January 18, 1894, three short papers of ours were printed to which Herr Freund has made very misleading references. The first proves that the alkaloild once obtained by Wright from aconite root, and called "Picraconitine," is not a pure substance, but consists chiefly of "Isaconitine," which we had previously shown to be benzoylaconine* (Trans., 1893,63, 448). The second paper shows that when aconitine is heated at its melting point it loses one molecular portion of acetic acid, forming a new alkaloid, pyraconitine. The third paper proves that acetic acid is formed, both when aconitine is converted into "isaconitine" by heating its salts with water, and also when aconitine is completely hydrolysed with formation of aconine, and, therefore, that it is probable the acetyl group of aconitine may be separated under both these conditions. Now the percentages of carbon and hydrogen in "isaconitine" represented by the old formula $\mathrm{C}_{33} \mathrm{H}_{45} \mathrm{NO}_{12}$, or by the new formula $\mathrm{C}_{31} \mathrm{H}_{43} \mathrm{NO}_{11}$, and also in aconine, using the two corresponding formulæ $\mathrm{C}_{26} \mathrm{H}_{41} \mathrm{NO}_{11}$ and $\mathrm{C}_{24} \mathrm{H}_{39} \mathrm{NO}_{10}$ are so nearly the same that proof as to the separation of one acetyl group from aconitine could not be obtained from the results of the ultimate analysis of these products; the elimination of the acetyl group making but little difference in the percentage composition.

$$
\begin{aligned}
& \text { Benzaconine }\left\{\begin{array}{l}
\mathrm{C}_{33} \mathrm{H}_{45} \mathrm{NO}_{12} \text { (old formula) } \mathrm{C}=61 \cdot 20 ; \mathrm{H}=6 \cdot 95 . \\
\mathrm{C}_{31} \mathrm{H}_{43} \mathrm{NO}_{11} \text { (new formula) } \mathrm{C}=61 \cdot 48 ; \mathrm{H}=7 \cdot 10 .
\end{array}\right. \\
& \text { Aconine } \ldots .\left\{\begin{array}{l}
\mathrm{C}_{26} \mathrm{H}_{41} \mathrm{NO}_{11} \text { (old formula) } \mathrm{C}=57 \cdot 46 ; \mathrm{H}=7 \cdot 55 . \\
\mathrm{C}_{24} \mathrm{H}_{39} \mathrm{NO}_{10} \text { (new formula) } \mathrm{C}=57 \cdot 48 ; \mathrm{H}=7 \cdot 78 .
\end{array}\right.
\end{aligned}
$$

The required proof, however, could be gained by estimating

* Until the simultaneous production of molecular equivalents of "isaconitine" and acetic acid had been established, it is clear that the experimental evidence strongly supported the hypothesis of isomerism. 
accurately the proportion of acetic acid separated in thes 3 changes. Now, on attempting to estimate exactly the quantity of acetic acid formed under these conditions, we met with unexpected difficulties, so that, at the time these short papers were written, quantitative estimations of the desired degree of accuracy had not been made. On this account, we were unable to do more than jndicate the nature of the conclusions at which we had arrived, and, for the same reason, we were obliged to retain the old formula for "isaconitine" in the first paper.* To have done otherwise would have been to anticipate the proof which could only be gained by exact quantitative determinations of acetic acid not, at that time, made; but we pointed out at the close of the third paper that if this view "should prove to be correct the nomenclature and formulæ of aconitine derivatives will need entire revision."

Wishing to complete this proof by making the necessary determinations of acetic acid, we only presented to the Society two full papers for the Transactions, holding over the third until these determinations had been made. In about a fortnight, these estimations were finished, and they prored that exactly one molecular proportion of acetic acid separates when aconitine changes into "isaconitine" or into aconine. Therefore, aconitine must be, as we had indicated in our third short paper, mentioned above as published in the Proceedings, an acetyl derivative which loses its acetyl group under these conditions.

The Berichte issued from Berlin on February 19, 1894 (p. 433) contained a short paper by Messrs. Frennd and Beck, their first contribution to the literature of aconitine, in which they stated that aconitine yields acetic acid on hydrolysis, but gave no estimations of the amount of acetic acid formed, or, indeed, any experimental proof of their assertion that aconitine is acetylbenzoglaconine. That they had seen our papers in the "Proceedings" is evident, from the fact that they actually quote from the first on "picraconitine," although they entirely ignore the two following papers, which not only indicate the conclusion they bring forward, but also supply experimental evidence of its truth. This proceeding seemed to us so unfair that we at once sent to the President of the Society a short statement of our quantitative determinations, at the same time drawing his attention to the paper of Messrs. Freund and Beck. The President directed that this statement should bo included in the March number of the Journal (1894), then passing through the press, in which the first two pxpers had already been printed. $\dagger$

* Herr Freund has put an entirely erroneous interpretation on this circuunstance.

+ Having looked into the fasts of the cuse this course had my entire approval. EDITOR. 
This third paper contains the only complete proof which has hitherto been adduced that aconitine is acetylbenzaconine, and it will be seen that it furnishes the results of estimations of acetic acid which, it was stated in our short paper published in the Proceedings nearly two months before, were in the process of being made.*

At the same time we sent to the German Chemical Society a statement, of our claim for priority, which was printed in the Berichte of March 19, 1894 (p. 664). In his first reply to this statement, $\dagger$ Herr Freund (Ber., 1894, 27, 720) attempts to justify the absence of any allusion by him to our short papers in the Proceedings, on the ground that the production of acetic acid had already been observed by Messrs. Ehrenberg and Purfürst in 1892, and that the work of these observers formed the basis of his inquiry.

Now Ehrenberg and Purfürst had boiled aconitine with water, and stated that they had identified in the product benzoic acid; methyl alcohol ; an acid, probably acetic acid; probably formic acid, together with the alkaloïds named (but neither described nor analysed) "picraconitine" and "napelline." They conclude, without quantitative proof, that aconitine first loses benzoic acid, forming picraconitine, then that picraconitine loses methyl alcohol, forming napelline, and, lastly, that napelline loses acetic acid, forming aconine. Messrs. Freund and Beck profess that it is these manifestly erroneous observations and conclusions which have led them to the very different result that aconitine is acetylbenzoylaconine, and that it loses acetic acid but not benzoic acid, forming "picraconitine." As a matter of fact, they reject every observation and conclusion arrived at by Ehrenberg and Purfürst, except the suggestion that acetic acid is probably a product of the decomposition of aconitine; that it is so was proved for the first time by us, and its true bearing indicated in our two shori papers; to these Messrs. Freund and Beck do not even refer, although they were published more than a month before.

With this plain statement of the facts of the case we can confidently nphold our claim to priority against Herr Freund's criticism.

Messrs. Freund and Beck have proposed to alter to $\mathrm{C}_{34} \mathrm{H}_{47} \mathrm{NO}_{11}$ the formula of aconitine which we give as $\mathrm{C}_{33} \mathrm{H}_{45} \mathrm{NO}_{12}$, and Herr Freund professes to be aggrieved that we have not so far cousidered his

* The circumstances under which the third paper was published prevented us from including in it the full discussion of our results which we had previously intended it to contain, and it is obvious that through inadvertency the formulæ for aconine and its derivatives are incorrectly printed in the tahle at the close of this paper, but they are correctly given in the text immediately above.

† Herr Freund states that he has not replied until now (Ber., 25, Feb., 1895, p. 192), but a reference to his paper in the Berichte of March 19, 1894, will show that the excuse he makes is wanting in accuracy. 
proposal.* As a matter of fact, any discussion at the present time as to the exact formula of aconitine must be futile, as, until simpler derivatives of aconitine have been prepared and analysed, the question must remain, to a large extent, an open one. At the same time, we may state that analyses of the aconitine derivatives recently prepared by us do not furnish any ground for adopting the formula which Herr Freund has prematurely advanced; on the contrary, they lead us to prefer that long ago proposed by ourselves (see Proc., February 18, 1895). This will be made clear by an inspection of the following table.

\begin{tabular}{|c|c|c|c|}
\hline & & \multicolumn{2}{|c|}{ Dunstan and Carr. } \\
\hline & Calculated. & Found. & Calculated. \\
\hline Triacetylaconitine $\ldots \ldots \ldots\{$ & 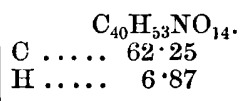 & $\begin{array}{r}60 \cdot 42 \\
6 \cdot 82\end{array}$ & $\begin{array}{c}\mathrm{C}_{39} \mathrm{H}_{51} \mathrm{NO}_{15} . \\
60 \cdot 54 \\
6 \cdot 59\end{array}$ \\
\hline Diacetylaconitine $\ldots \ldots \ldots\{$ & 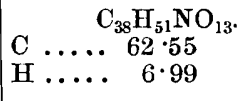 & $\begin{array}{r}60 \cdot 98 \\
7 \cdot 06\end{array}$ & $\begin{array}{c}\mathrm{C}_{37} \mathrm{H}_{49} \mathrm{NO}_{14} \\
60 \cdot 74 \\
6 \cdot 70\end{array}$ \\
\hline Pyraconitine hydrobromide \{ & 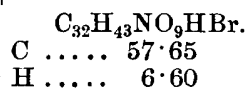 & $\begin{array}{r}55 \cdot 80 \\
6 \cdot 28\end{array}$ & $\begin{array}{c}\mathrm{C}_{31} \mathrm{H}_{41} \mathrm{NO}_{10} \mathrm{HBr} . \\
55 \cdot 69 \\
6 \cdot 28\end{array}$ \\
\hline Aconine..$\ldots \ldots$ & 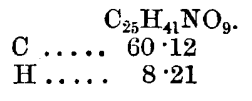 & $\begin{array}{r}57 \cdot 31 \\
8 \cdot 02\end{array}$ & $\begin{array}{c}\mathrm{C}_{24} \mathrm{H}_{39} \mathrm{NO}_{10} \\
57 \cdot 48 \\
7 \cdot 78\end{array}$ \\
\hline
\end{tabular}

Messrs. Freund and Beck have also attempted to show that the isomeric forms of aconitine aurichlorides, as well as aurichlorbenzaconine, described by one of us and Mr. H. A. D. Jowett (Trans., 1894), do not exist, but it has been shown (Proc., February 18, 1895), by a re-examination of these compounds, that our original observations are correct.

Research Laboratory,

Pharmaceutical Society,

London.

* It will be evident that our new formula for benzaconine, $\mathrm{C}_{31} \mathrm{H}_{45} \mathrm{NO}_{11}$, which Herr Freund asserts is based solely on the analysis of the aurichlor-derivative (the existence of which, by the way, he denies), rests chiefly on the demonstration that exactly one molecular proportion of acetic acid accompanies its production from aconitine. 